\title{
A Theory of Tax Avoidance - Managerial Incentives for Tax Planning in a Multi-Task Principal-Agent Model
}

\author{
Ralf Ewert \\ Rainer Niemann
}

CESIFO WORKING PAPER NO. 4851

CATEGORY 1: Public FinANCE

JUNE 2014

\footnotetext{
An electronic version of the paper may be downloaded

- from the SSRN website:

- from the RePEc website:

wWw.SSRN.com

www.RePEc.org

- from the CESifo website:

www.CESifo-group.org/wp
}

\section{CESifo}




\title{
A Theory of Tax Avoidance - Managerial Incentives for Tax Planning in a Multi-Task Principal-Agent Model
}

\begin{abstract}
We derive determinants of tax avoidance by means of a multi-task principal-agent model. We extend prevailing models by integrating both corporate and individual income taxation as well as by including tax planning effort in the agent's action portfolio. Our model shows novel and apparently paradoxical results regarding the impact of increased tax rates on efforts, risks, and incentive schemes. First, the principal's after-tax profit can increase with a higher corporate tax rate. Second, tax planning effort can decrease in the corporate tax rate. Third, operational effort can increase with increasing corporate tax rates. We show that differences in productivities, differences in operational and tax risk and the correlations of these risks are crucial determinants for the optimal degree of tax avoidance. These determinants can explain why some firms are more tax aggressive than others and should therefore be considered in empirical studies. Related to this insight, we demonstrate that our results are consistent with recent empirical evidence.
\end{abstract}

JEL-Code: H240, H250, M410.

Keywords: tax avoidance, principal-agent theory, tax planning, multi-task models, corporate governance.

\author{
Ralf Ewert \\ University of Graz \\ Center for Accounting Research \\ Universitätsstraße 15 \\ Austria - 8010 Graz \\ ralf.ewert@uni-graz.at
}

\author{
Rainer Niemann* \\ University of Graz \\ Center for Accounting Research \\ Universitätsstraße 15 \\ Austria-8010 Graz \\ niemann@uni-graz.at
}

*corresponding author 


\section{A Theory of Tax Avoidance -}

\section{Managerial Incentives for Tax Planning in a Multi-Task Principal-Agent Model}

\section{Introduction}

Prior literature suggests that effective tax rates vary widely across firms, indicating that managers and shareholders of different firms have different preferences regarding their tax strategy in terms of risk or tax reporting aggressiveness. The - predominantly empirical - tax avoidance literature provides a variety of explanations why some firms are more tax aggressive than others, for example, family ownership, industry characteristics, or profitability. Although corporate governance quality is regularly used as an independent variable to explain tax reporting behavior, analytical models of corporate governance are rarely applied in the tax avoidance literature. Thus, empirical models are exposed to the risk of omitting crucial determinants of tax avoidance.

By contrast, the corporate governance literature often analyzes the relationship between shareholders and managers in corporations with a separation of ownership and control by principal-agent models. These models study the structural characteristics of incentive contracts under various settings comprising, e.g., risk preferences, task productivities, informational distributions, duration of agency relationships, options for renegotiation etc.

A puzzling phenomenon of the principal-agent literature is the widespread negligence of 
tax effects and especially tax planning activities. The models' objective functions typically involve maximizing the principal's expected potential of financial consumption net of managerial remuneration. The fact that in reality, both principals and agents are subject to various taxes is rarely incorporated, although taxes are an important factor for the determination of the amounts that are left for consumption. (According to OECD (2013a, 2013b) top statutory personal income tax rates were between $15,0 \%$ and $60,2 \%$ (average: 42,5\%) and corporate tax rates between 12,5\% and 39,1\% (average: 25,5\%) in the OECD countries in 2012.) Therefore, except for a few papers mentioned in the literature review below, there is relatively little knowledge with respect to the impact of taxation on the design of incentive schemes. We actually do not know whether and to what extent corporate and individual taxation affect the optimal contract parameters. The extant literature can be interpreted as tacitly assuming that the incorporation of tax effects would essentially leave intact the qualitative results of the no-tax analysis. However, the validity of such a procedure needs some verification that requires an explicit analysis of models including tax parameters.

In order to study the consequences of taxes on optimal incentive schemes, one has to take into account that the response of economic actors on taxes manifests not only in a change of "real" actions (like, e.g., operational efforts, change of incentive schemes, investment activities etc.) but also in deliberate efforts to avoid taxes given any "real" actions. For example, the legal structure of transactions can be optimized, transfer prices can be adjusted, tax shelters might be utilized, etc. Tax planning, of course, requires managerial effort and qualifications that are different from operational effort and 
operational qualifications. Hitherto, it is unexplored whether and to what extent a tradeoff between operational effort and tax planning effort arises and whether tax planning should be explicitly incentivized in remuneration contracts. ${ }^{1} \mathrm{~A}$ model that explains these phenomena could contribute significantly to the theoretical basis for the empirical literature on tax avoidance. ${ }^{2}$

This paper is intended to bring together the tax avoidance literature and the principalagent literature by employing a multi-task principal-agent model of the LEN type. To address the issue of separate efforts to avoid taxes, we build on models that are now heavily employed in the literature on earnings management. ${ }^{3}$ In our setting the principal offers a linear compensation contract to the agent who can provide operational effort as well as tax planning effort. As a generally accepted definition of tax avoidance (or tax aggressiveness) is still missing, we regard tax avoidance as "downward management of taxable income through tax planning activities" (Chen et al., 2010, fn 1) and use the term "tax planning" equivalently. The agent's remuneration consists of a fixed salary and a performance-related compensation based on the principal's after-tax cash flow. This contract motivates both operational efforts and tax planning.

Our model captures both wage taxes for the managerial remuneration and corporate taxes for the principal's income. While the effects of the wage tax rate are as expected (i.e., both managerial efforts as well as the principal's after-tax profit decrease with

\footnotetext{
${ }^{1}$ For an empirical analysis of the determinants of tax directors' remuneration see Armstrong et al. (2012).

${ }^{2}$ See, for instance, Cloyd et al. (1996), Frank et al. (2009), Chen et al. (2010), Hanlon/Slemrod (2009), Rego/Wilson (2012). A theoretical model of financial accounting measures and tax aggressiveness is given in De Waegenaere et al. (2010).

${ }^{3}$ See Ewert/Wagenhofer (2012) for more details.
} 
increasing the wage tax rate), we derive completely novel results with respect to a variation of the corporate tax rate and identify normal as well as apparently paradoxical tax effects. Depending on the risk structure, operational effort, tax planning effort, the bonus coefficient and the principal's after-tax profit can increase or decrease with higher corporate tax rates. These ambiguous results of corporate taxes have not been shown in the existing literature. They are due to subtle interrelationships between taxes, the productivities of different efforts, risks and the adjustment of the incentive scheme. The results provide a basis for an assessment of the potential effects that a change in tax rates may have on efforts, risks and the utility of parties involved in an agency relationship. We further find some crucial determinants of tax planning that have largely been neglected in the empirical tax avoidance literature, among them productivity differentials of operational and tax planning effort, differences in operational risk and tax risk, and the correlation of these risks. Integrating these variables could substantially improve the explanatory power of empirical studies. We demonstrate that our results are consistent with recent evidence that takes into account some of the parameters that are relevant in our theory.

The remainder of this paper is organized as follows. Section 2 provides a compact literature review. Section 3 introduces the model and presents results. Section 4 summarizes and gives suggestions for further research. 


\section{Literature Review}

Despite the extensive analytical literature on tax evasion as illegal form of tax avoidance beginning with Allingham/Sandmo (1972), few papers take the managerial impact on tax avoidance explicitly into account. For example, Crocker/Slemrod (2005) analyze corporate tax evasion in an agency setting and derive optimal incentive compensation schemes for corporate tax managers taking into account the enforcement policies of fiscal authorities. They find that penalties imposed on the tax manager are more effective in reducing evasion than are those imposed on shareholders.

Chen/Chu (2005) propose a theoretical model on corporate income tax evasion. According to their results, tax evasion increases the profit retained by the firm. The reason is the incomplete contract due to the illegal nature of tax evasion. Therefore, the costs not only comprise the risk of being detected, but also the costs of efficiency loss in internal control.

Desai/Dharmapala (2006) formulate and empirically test a model of corporate tax sheltering and managerial incentive contracts. They find that increases in incentive compensation tend to reduce the level of tax sheltering and identify a complementary relationship between diversion and sheltering.

In contrast to the literature on tax evasion, the recent literature on the determinants of (either legal or illegal) tax avoidance is predominantly empirical. Hanlon/Slemrod (2009) conjecture that corporate governance affects the capital market reaction on press releases concerning tax sheltering. Using a scoring model of corporate governance 
they find that poorly governed firms face a more negative capital market reaction.

Regarding family ownership as another determinant of corporate governance, Chen et al. (2010) report that family firms tend to be less tax aggressive than their non-family counterparts. By contast, Bauweraerts/Vandernoot (2013) use a Belgian sample and find a positive relationship between family involvement and tax aggressive reporting.

Except for the papers mentioned, the tax aggessiveness literature and the corporate governance/principal-agent literature hardly overlap. Taxes do not play a major role in the principal-agent literature. In particular, the fact that managers have some discretion on tax planning is almost completely neglected in principal-agent theory. With the exceptions mentioned above, we are not aware of papers that model tax planning actions explicitly as a managerial action variable.

As the integration of taxes into principal-agent models does not follow a clear pattern, there exists a variety of different tax-related research questions, for example, the leaseor-buy decision (Wolfson, 1985), risk sharing arrangements in partnerships (Fellingham/Wolfson, 1985), the effects of taxation under limited liability (Banerjee/Besley, 1990), the effects of bonus taxation (Radulescu, 2012), or the incentive effects of employer-provided workplace benefits (Voßmerbäumer, 2013).

As far as we know, Niemann (2008) represents currently the only multi-task agency model including taxation. He investigates the impact of a tax system that differentiates between investment projects with different risk characteristics. In this model a tax base reduction favors risky projects, whereas a tax rate reduction for risky projects induces 
ambiguous results, depending on the manager's degree of risk aversion. However, tax planning is not considered as a separate decision variable.

Many principal-agent-tax papers are based on the LEN model that was first presented by Spremann (1987). The main advantage of this approach is the existence of analytical solutions. Hemmer (2004) criticizes the restrictive non-tax assumptions of the LEN model. Holmström/Milgrom (1987) provide justifications for the linearity assumption.

Originally, the LEN model was designed with a single action variable of the agent. Multitask extensions of the model, for example Holmström/Milgrom (1991), Feltham/Xie (1994) and Datar et al. (2001), permit multiple managerial action variables. However, to our knowledge tax planning effort and its interplay with operational effort has not yet been explored in an agency setting. This paper contributes to several research areas: First we extend the principal-agent literature by a detailed analysis of tax effects, second we address the tax avoidance literature by deriving hitherto neglected determinants and explanations for differentials in the tax aggressiveness of firms. In contrast to Desai/Dharmapala (2006) we derive explicit solutions for the optimal level of tax planning and its determinants. Furthermore, we integrate corporate as well as personal income taxation and point to some previously unexplored effects of corporate taxation. 


\section{Multi-task LEN model}

\section{1. $\quad$ Model setup}

In our model the owner of a corporation (principal) delegates the direction of the company to a manager (agent) who has special knowledge and qualifications for this job. The principal's after-tax cash flow as the relevant financial objective variable depends on the agent's actions and one or more random variables. The agent can exert two distinct efforts, i.e., operational effort and tax planning effort. These efforts are not observable. The principal cannot infer the agent's effort levels from the realization of the cash flows. Otherwise, a forcing contract could be written. The agent suffers from increasing and convex disutilities of effort. The agent's utility function is known to both parties. The principal is risk-neutral; the agent is risk-averse.

The principal offers the agent a performance-based compensation. The compensation parameters are chosen to maximize the principal's utility. To accept the offer the agent must reach at least his reservation utility. The agent determines his optimal efforts given the parameters offered in the compensation contract.

We use a multi-task version of the LEN model as a special case of the standard principalagent model. ${ }^{4}$ The LEN assumptions mean that

- the principal's gross cash flow $x$ is linear in the agent's effort(s),

- the agent's compensation $s$ is linear in a performance measure $m: s(m)=S_{0}+\alpha m$,

${ }^{4}$ For the general properties of LEN models see Spremann (1987). 
with $S_{0}$ as fixed salary, $\alpha \geq 0$ and $\alpha m$ as performance-based compensation,

- the agent's utility function $U^{A}$ is negative exponential with constant absolute risk aversion: $U^{A}(s, a)=-\exp [-r(s-V(a))]$, where $r$ denotes the Arrow-Pratt measure and $V(a)$ is the agent's disutility of effort,

- all random variables are normally distributed.

Operational effort is the first managerial action variable. Operational cash flow $x$ is a linear function of a non-negative operational effort $a: x=k_{x} a+\theta_{x}$ with $\theta_{x}$ as a normally distributed random variable with zero mean and variance $\sigma_{x}^{2}: \theta_{x} \sim N\left(0, \sigma_{x}^{2}\right)$. The parameter $k_{x}$ denotes the efficiency of operational effort. In accordance with the literature, ${ }^{5}$ the agent's disutility of operational effort is given by $V(a)=a^{2} / 2$.

Before referring to the second managerial action variable, the tax system must be defined. At the principal's level, corporate taxation applies. The proportional corporate tax rate is denoted by $\tau^{P}$. The corporate tax base is defined as the difference of taxable operational cash flows $x$ and deductible managerial remuneration $s$. We assume that deductibility limits do not apply. ${ }^{6}$ At the agent's level, remuneration is fully subject to the wage tax at the proportional rate $\tau^{A}$, so that the after-tax remuneration $s^{\tau}$ amounts to $s^{\tau}=\left(1-\tau^{A}\right) s$. Disutility of effort is non-deductible, because no direct cash flows are associated with the disutilities. The agent's utility function and the disutility-of-effort

\footnotetext{
${ }^{5}$ See, for example, Wagenhofer (2003), p. 291, Hemmer (2004), p. 155, Niemann (2008), p. 279.

${ }^{6}$ For the incentive effects of deductibility limits see Halperin et al. (2001) and Göx (2008).
} 
functions are exogenous and hence unaffected by taxation.

In general, the monetary equivalent $\underline{u}^{\tau}$ of the agent's after-tax reservation utility can be a function of the wage tax rate: $\underline{u}^{\tau}=\underline{u}^{\tau}\left(\tau^{A}\right)$ with $\partial \underline{u}^{\tau} / \partial \tau^{A} \leq 0$ and may therefore differ from the corresponding pre-tax values. ${ }^{7}$ However, more specific statements concerning the functional relation between the wage tax rate and after-tax reservation utility require extensive information on the conditions of alternative employment contracts and the managerial labor market. Since none of our results depend on the level of $\underline{u}^{\tau}$, we set $\underline{u}^{\tau}=0$ to simplify the formal analysis.

Given the above specifics of the tax system, after-tax operational cash flow amounts to $x^{\tau}=\left(1-\tau^{P}\right) x$. Apart from operational effort $a$ that affects operational cash flow $x$, the agent can exert tax planning effort that reduces the principal's expected tax liability. Tax planning is interpreted broadly and not limited to particular tax types. It can refer to income taxes, transaction taxes, property taxes, tariffs, fees of all kinds and can be legal (tax avoidance) or illegal (tax evasion). For instance, tax planning effort includes the optimal exercise of options granted by the tax law, e.g. the optimal choice of depreciation methods, the optimal legal design of transactions, choosing the legal structure of subsidiaries, optimizing transfer prices, or other tax sheltering activities. In order to preserve tractability and to keep the analysis as parsimonious as possible, we represent all tax planning activities by the single continuous and non-negative variable $b$

\footnotetext{
${ }^{7}$ For the different interpretations of after-tax reservation utilities see Niemann (2008), p. 284.
} 
that can be chosen independently of operational effort. ${ }^{8}$ Henceforth, we define a higher degree of tax avoidance by higher levels of tax planning effort $b$.

The effect of tax planning is uncertain. There is no guarantee that high tax planning effort will finally be rewarded by tax reductions, so that the actual effort level cannot be inferred from the realized tax liability. The reason is that real-world tax systems are subject to various sources of uncertainty. ${ }^{9}$ Unexpected tax reforms frequently modify tax rates and tax bases. Fiscal authorities and tax courts might interpret tax laws and economic facts in different ways than taxpayers. Moreover, it is uncertain whether tax returns are audited by the fiscal authorities, how strict possible tax audits are carried out and whether activities of tax evasion are detected. Total tax risk comprises firmspecific and industry-specific tax risks as well as country-specific risks.

In accordance with the LEN assumptions, we assume that the tax base reduction is linear in tax planning effort $b: y=k_{y} b+\theta_{y}$. Consequently, the reduction of the principal's tax liability is $y^{\tau}=\tau^{P} y . k_{y}$ denotes the efficiency parameter for tax planning, meaning that highly skilled tax managers have high values of $k_{y} . \theta_{y} \sim N\left(0, \sigma_{y}^{2}\right)$ is the random variable representing tax risk. We do not distinguish between different sources of tax risk; all tax risks are summarized by the parameter $\sigma_{y}^{2}$.

\footnotetext{
8 Phillips (2003) carries out an empirical study on the effects of after-tax performance measures on the corporate effective tax rate. Armstrong et al. (2012) find a significant negative relationship of tax directors' incentive compensation and the GAAP effective tax rate. Dyreng et al. (2010) find that individual executives have substantial influence on the level of firms' tax avoidance.

${ }^{9}$ Investment effects of tax uncertainty are analyzed by Niemann $(2004,2011)$.
} 
The random variables $\theta_{x}$ and $\theta_{y}$ can basically be correlated in any direction: $\sigma_{x y}=\sigma_{x} \sigma_{y} \rho_{x y}$, with $\sigma_{x y}$ as the covariance and $\rho_{x y} \in[-1 ; 1]$ as the correlation coefficient. Fiscal policy and fiscal administration provide some reasons why operational risk and tax risk could be correlated. For instance, tax reform activities are pro-cyclical $\left(\rho_{x y}>0\right)$ in some jurisdictions and counter-cyclical $\left(\rho_{x y}<0\right)$ in others. Tax audit probability and rigor of tax audits can be either higher $\left(\rho_{x y}>0\right)$ or lower $\left(\rho_{x y}<0\right)$ if tax revenues are low due to a recession. These examples indicate that there is no universal a priori specification of the algebraic sign of $\rho_{x y}$. In addition, the correlation coefficient can vary across firms, because a firm's or an industry's business cycle can differ from macroeconomic cycles.

The principal's total after-tax cash flow before deducting remuneration costs is given by $x^{\tau}+y^{\tau}$ with an expected value of $E\left[x^{\tau}+y^{\tau}\right]=\left(1-\tau^{p}\right) k_{x} a+\tau^{p} k_{y} b$.

In accordance with the agent's disutility of operational effort we assume $V(b)=b^{2} / 2$ for the disutility of tax planning effort. Consequently, the agent's after-tax certainty equivalent $C E$ can be written as: $C E=E\left[s^{\tau}\right]-V(a)-V(b)-\frac{r}{2} \operatorname{Var}\left[s^{\tau}\right]$. 


\subsection{Observable Efforts}

As a benchmark case we consider observable efforts, so that the principal can directly determine and enforce the desired effort levels. In this case only the participation constraint must be fulfilled to ensure that the agent accepts the employment contract. The participation constraint requires that the agent receives at least his after-tax reservation utility: $C E=\underline{u}^{\tau}=0$. Assuming a risk neutral principal, observable efforts imply that a fixed salary $S_{0}$ without variable compensation is optimal. Since the participation constraint must hold with equality, it follows that $\left(1-\tau^{A}\right) S_{0}=\frac{1}{2} a^{2}+\frac{1}{2} b^{2}$, so that the pre-tax fixed salary amounts to $S_{0}=\frac{1}{1-\tau^{A}}\left(\frac{1}{2} a^{2}+\frac{1}{2} b^{2}\right)$.

The principal's objective function $N$ is defined by the expected after-tax operational cash flows less deductible managerial compensation plus expected reduction of the tax liability caused by tax-planning efforts:

$$
N=E\left[\left(1-\tau^{P}\right)\left(x-S_{0}\right)+\tau^{P} y\right]=\left(1-\tau^{P}\right) k_{x} a-\frac{1-\tau^{P}}{1-\tau^{A}}\left(\frac{1}{2} a^{2}+\frac{1}{2} b^{2}\right)+\tau^{P} k_{y} b
$$

The optimal effort levels $\left(a^{f}, b^{f}\right)$ are:

$$
\begin{aligned}
& \frac{\partial N}{\partial a}=\left(1-\tau^{P}\right) k_{x}-\frac{1-\tau^{P}}{1-\tau^{A}} a^{f}=0 \quad \Rightarrow \quad a^{f}=\left(1-\tau^{A}\right) k_{x}, \\
& \frac{\partial N}{\partial b}=\tau^{P} k_{y}-\frac{1-\tau^{P}}{1-\tau^{A}} b^{f}=0 \Rightarrow b^{f}=\left(1-\tau^{A}\right) \frac{\tau^{P}}{1-\tau^{P}} k_{y} .
\end{aligned}
$$


Optimal operational effort is unaffected by the corporate tax rate $\tau^{P}$ and depends negatively on the agent's wage tax rate $\tau^{A}$. Increasing the wage tax rate reduces the optimal operational effort as well as the optimal tax planning effort, because higher wage taxes require a higher salary to compensate the agent for a given effort, thus making each level of effort more expensive for the principal. This holds for both types of effort, and the relation between the optimal effort levels depends on the individual productivities as well as on the corporate tax rate: $\frac{a^{f}}{b^{f}}=\frac{\left(1-\tau^{p}\right)}{\tau^{p}} \frac{k_{x}}{k_{y}}$ Obviously, tax planning becomes more attractive for higher corporate tax rates $\left(\partial b^{f} / \partial \tau^{P}>0\right) .{ }^{10}$

Even without further considering corporate governance properties eq. (2) provides a reason for tax aggressiveness differentials between firms. The optimal degree of tax aggressiveness depends on tax planning productivity. Different agents in different firms with different productivities will therefore provide different effort combinations. In addition, personal as well as corporate tax rate differentials explain why some agents are more tax aggressive than others.

Substituting the optimal efforts $a^{f}$ and $b^{f}$ yields the principal's expected net cash flow:

${ }^{10}$ To avoid infinite values we confine our analysis to tax rates strictly below $100 \%: \tau^{A}, \tau^{P} \in[0,1)$ 


$$
\begin{aligned}
N & =\left(1-\tau^{P}\right)\left(1-\tau^{A}\right) k_{x}^{2}+\frac{1-\tau^{A}}{1-\tau^{P}}\left(\tau^{P}\right)^{2} k_{y}^{2}-\frac{1-\tau^{P}}{1-\tau^{A}}\left[\frac{1}{2}\left(1-\tau^{A}\right)^{2} k_{x}^{2}+\frac{1}{2}\left(\tau^{P}\right)^{2}\left(\frac{1-\tau^{A}}{1-\tau^{P}}\right)^{2} k_{y}^{2}\right] \\
& =\frac{1}{2} \cdot \frac{1-\tau^{A}}{1-\tau^{P}} \underbrace{\left.\left(1-\tau^{P}\right)^{2} k_{x}^{2}+\left(\tau^{P}\right)^{2} k_{y}^{2}\right]}_{:=K} .
\end{aligned}
$$

Consistent with intuition, we define an effect of increasing the corporate tax rate as "normal" when the operational effort decreases, tax planning effort increases, and the expected net cash flow decreases. "Paradoxical" tax effects are defined as the opposite. With observable efforts, it follows from (2) that we get "neutral" effects for the operational effort and normal effects for tax planning. Furthermore, in a model without tax planning (this is equivalent to setting $k_{y}=0$ ) a simple inspection of (3) reveals that the principal's objective function also displays normal behavior for each level of corporate tax rates. However, as the following proposition states, in a setting with tax planning the principal's expected net cash flow behaves always paradoxically for sufficiently high corporate tax rates:

Proposition 1: For any combination of strictly positive productivities there exists a unique critical corporate tax rate $\bar{\tau}^{P} \in(0,1)$ such that the principal's objective function increases for all corporate tax rates exceeding $\bar{\tau}^{P}$.

Proof: From the partial derivative of $N$ it follows that: 
$\frac{\partial N}{\partial \tau^{P}}=\frac{1}{2} \cdot\left(1-\tau^{A}\right)\left[\frac{\tau^{P}\left(2-\tau^{P}\right)}{\left(1-\tau^{P}\right)^{2}} k_{y}^{2}-k_{x}^{2}\right] \geq 0 \Leftrightarrow \underbrace{\frac{\tau^{P}\left(2-\tau^{P}\right)}{\left(1-\tau^{P}\right)^{2}}}_{:=q\left(\tau^{P}\right)} \geq\left(\frac{k_{x}}{k_{y}}\right)^{2}>0$

Since $\left.q\right|_{\tau^{P}=0}=0, \lim _{\tau^{P} \rightarrow 1} q\left(\tau^{P}\right)=+\infty$ and $\frac{d q}{d \tau^{P}}>0$, there is exactly one value $\bar{\tau}^{P} \in(0,1)$ such that condition (4) is fulfilled for $\tau^{P} \geq \bar{\tau}^{P}$.

With high corporate tax rates, the marginal benefits of tax planning by increasing the corporate tax rate outweigh the marginal loss in net operating cash flows after managerial remuneration. According to (4), the exact level of the critical corporate tax rate $\bar{\tau}^{P}$ depends on the relation between the productivities of operational efforts and tax planning. If the operational productivity is much larger than the productivity of tax planning, the critical value $\bar{\tau}^{P}$ would also be relatively large, making it unlikely in those scenarios that the paradoxical case would occur for realistic tax rates.

\subsection{Unobservable efforts}

If efforts are non-observable, the principal has to offer a performance-based compensation contract to ensure that the agent provides the desired effort levels. We consider a scenario with a single performance measure $m$ that is defined by the after-tax cash flow before deducting remuneration costs, i.e., $m=\left(1-\tau^{P}\right) x+\tau^{P} y$. This is motivated by the principal's desire to induce both operational and tax planning efforts. 
Since the impact of tax planning shows up in tax savings, an after-tax measure is appropriate to provide incentives for tax planning activities.

Gross managerial compensation is thus defined as $S_{0}+\alpha\left[\left(1-\tau^{P}\right) x+\tau^{P} y\right]$, with $\alpha$ as the bonus coefficient attached to the performance measure.

Inserting the agent's net compensation after wage taxation

$s^{\tau}=\left(1-\tau^{A}\right)\left[S_{0}+\alpha\left[\left(1-\tau^{P}\right) x+\tau^{P} y\right]\right]=\left(1-\tau^{A}\right) S_{0}+\alpha\left(1-\tau^{A}\right)\left[\left(1-\tau^{P}\right) x+\tau^{P} y\right]$

gives the after-tax certainty equivalent:

$C E=\left(1-\tau^{A}\right)\left[S_{0}+\left(1-\tau^{P}\right) \alpha k_{x} a+\tau^{P} \alpha k_{y} b\right]-\frac{1}{2} a^{2}-\frac{1}{2} b^{2}-\frac{r}{2}\left(1-\tau^{A}\right)^{2} \alpha^{2} \sigma^{2}$,

with $\sigma^{2}=\left(1-\tau^{P}\right)^{2} \sigma_{x}^{2}+\left(\tau^{P}\right)^{2} \sigma_{y}^{2}+2 \tau^{P}\left(1-\tau^{P}\right) \sigma_{x} \sigma_{y} \rho_{x y}$.

Optimizing the certainty equivalent with respect to $a$ and $b$ leads to the agent's optimal effort levels:

$$
\begin{aligned}
& \frac{\partial C E}{\partial a}=\left(1-\tau^{A}\right)\left(1-\tau^{P}\right) \alpha k_{x}-a=0 \Rightarrow a^{*}=\left(1-\tau^{A}\right)\left(1-\tau^{P}\right) \alpha k_{x} \\
& \frac{\partial C E}{\partial b}=\left(1-\tau^{A}\right) \tau^{P} \alpha k_{y}-b=0 \Rightarrow b^{*}=\left(1-\tau^{A}\right) \tau^{P} \alpha k_{y} .
\end{aligned}
$$

Using the binding participation constraint $C E=\underline{u}^{\tau}=0$ the agent's expected remuneration before wage taxation can be written as: 
$E[s]=\frac{1}{2} \cdot \alpha^{2}\left(1-\tau^{A}\right)\left(K+r \sigma^{2}\right) \quad$ with $\quad K=\left(1-\tau^{P}\right)^{2} k_{x}^{2}+\left(\tau^{P}\right)^{2} k_{y}^{2}$

Using (9) and substituting the optimal effort levels from (7) and (8) permits to compute the principal's expected net cash flow after remuneration costs as a function of the bonus coefficient $\alpha$ only:

$N=K\left(1-\tau^{A}\right) \alpha-\frac{1}{2} \cdot\left(1-\tau^{P}\right)\left(1-\tau^{A}\right) \alpha^{2}\left(K+r \sigma^{2}\right)$

Optimizing this objective function with respect to the bonus coefficient $\alpha$ yields :

$\frac{\partial N}{\partial \alpha}=K\left(1-\tau^{A}\right)-\alpha\left(1-\tau^{A}\right)\left(1-\tau^{P}\right)\left(K+r \sigma^{2}\right)=0 \Rightarrow \alpha^{*}=\frac{K}{\left(1-\tau^{P}\right)\left(K+r \sigma^{2}\right)}$

Inspection of (11) shows that the optimal bonus coefficient increases directly in the corporate tax rate due to the term $1-\tau^{P}$ in the denominator and may even exceed unity for high corporate tax rates. Together with potentially positive fixed remunerations $S_{0}$ this seems to imply that the principal cannot collect positive cash flows for high corporate tax rates. This apparent contradiction dissolves if the principal's objective function given the optimal $\alpha^{*}$ is written as follows:

$$
\begin{aligned}
N & =E\left\{\left(1-\tau^{P}\right)\left[x-S_{0}^{\tau}-\alpha^{*}\left(\left(1-\tau^{P}\right) x+\tau^{P} y\right)\right]+\tau^{P} y\right\} \\
& =\left(1-\tau^{P}\right)\left[k_{x} a-S_{0}^{\tau}-\alpha^{*}\left(\left(1-\tau^{P}\right) k_{x} a+\tau^{P} k_{y} b\right)\right]+\tau^{P} k_{y} b \\
& =\left[1-\left(1-\tau^{P}\right) \alpha^{*}\right] \cdot\left[\left(1-\tau^{P}\right) k_{x} a+\tau^{P} k_{y} b\right]-\left(1-\tau^{P}\right) S_{0}^{\tau} \\
& =\left(1-\frac{K}{K+r \sigma^{2}}\right) \cdot\left[\left(1-\tau^{P}\right) k_{x} a+\tau^{P} k_{y} b\right]-\left(1-\tau^{P}\right) S_{0}^{\tau} .
\end{aligned}
$$


Thus, the effective bonus coefficient is $\left(1-\tau^{P}\right) \alpha$ rather than $\alpha$, so that for extremely high tax rates very high levels of $\alpha$ can be optimal without implying a negative objective value for the principal. The reason for this effect is that the variable compensation is based on the after-tax cash flow. Thus, the "net" bonus coefficient $\alpha\left(1-\tau^{P}\right)$ after corporate taxes would not be directly affected by the corporate tax rate. To achieve this, the nominal bonus parameter $\alpha$ has to be adapted by dividing $K /\left(K+r \sigma^{2}\right)$ by $\left(1-\tau^{P}\right)$.

The optimal efforts using the bonus coefficient from (11) are defined by:

$$
\begin{aligned}
& a^{*}=\left(1-\tau^{A}\right)\left(1-\tau^{P}\right) \alpha k_{x}=\left(1-\tau^{A}\right) \frac{K k_{x}}{K+r \sigma^{2}} \\
& b^{*}=\left(1-\tau^{A}\right) \tau^{P} \alpha k_{y}=\frac{\left(1-\tau^{A}\right) \tau^{P}}{1-\tau^{P}} \frac{K k_{y}}{K+r \sigma^{2}} .
\end{aligned}
$$

In the optimum, the principal's expected net cash flow is:

$$
N=\frac{1}{2} \cdot \frac{\left(1-\tau^{A}\right) K^{2}}{\left(1-\tau^{P}\right)\left(K+r \sigma^{2}\right)} .
$$

Note that the relation between the optimal unobservable effort levels is the same as under observability, i.e.

$$
\frac{a^{*}}{b^{*}}=\frac{\left(1-\tau^{p}\right)}{\tau^{p}} \frac{k_{x}}{k_{y}}=\frac{a^{f}}{b^{f}},
$$

but the respective magnitudes differ due to the trade-off between incentives and risk 
that is reflected in the scaling factor $K /\left(K+r \sigma^{2}\right)<1$.

Different from the observability case, the principal can no longer separately fix both efforts, which are now induced indirectly by giving incentives based on the performance measure $m$. Thus, both efforts are linked through the incentive parameter $\alpha$. The effects of varying the corporate tax rate are not obvious because $a^{*}, b^{*}, N, \alpha^{*}$ are directly affected by $\tau^{P}$ and indirectly via $K\left(\tau^{P}\right)$ as well as $\sigma^{2}\left(\tau^{P}\right)$.

Proposition 2: Operational effort $a^{*}$ always increases in the corporate tax rate if tax planning is riskless. Otherwise, it can increase or decrease in the corporate tax rate.

Proof: Differentiating (13) with respect to $\tau^{P}$ and simplifying leads to:

$$
\frac{\partial a^{*}}{\partial \tau^{P}}=\underbrace{\frac{2 r k_{x}\left(1-\tau^{A}\right)}{\left(K+r \sigma^{2}\right)^{2}}}_{>0} \underbrace{\left[k_{y}^{2} \tau^{P}\left(\sigma_{x}^{2}\left(1-\tau^{P}\right)+\rho_{x y} \sigma_{x} \sigma_{y} \tau^{P}\right)-k_{x}^{2}\left(1-\tau^{P}\right)\left(\sigma_{y}^{2} \tau^{P}+\rho_{x y} \sigma_{x} \sigma_{y}\left(1-\tau^{P}\right)\right)\right]}_{:=B}
$$

If tax planning is riskless, we have $\sigma_{y}^{2}=0$, making the term $B$ in brackets positive which implies that operational effort strictly increases in the corporate tax rate. Otherwise, for $\sigma_{y}>0$, the algebraic sign of this partial derivative depends on the correlation coefficient $\rho_{x y}$. The simplest case is $\rho_{x y}=0$, i.e., the risks are 
uncorrelated. Here we get

$$
\left.\frac{\partial a^{*}}{\partial \tau^{P}}\right|_{\rho_{x y}=0}\left\{\begin{array}{l}
> \\
= \\
<
\end{array}\right\} 0 \Leftrightarrow \frac{k_{y}}{\sigma_{y}}\left\{\begin{array}{l}
> \\
= \\
<
\end{array}\right\} \frac{k_{x}}{\sigma_{x}}
$$

If there is non-zero correlation, four cases have to be distinguished:

1. $\rho>-\frac{\sigma_{x}}{\sigma_{y}} \cdot \frac{1-\tau^{P}}{\tau^{P}} \wedge \rho>-\frac{\sigma_{y}}{\sigma_{x}} \cdot \frac{\tau^{P}}{1-\tau^{P}}$ :

$$
\frac{\partial a^{*}}{\partial \tau^{P}}\left\{\begin{array}{l}
> \\
= \\
<
\end{array}\right\} 0 \Leftrightarrow\left(\frac{k_{y}}{k_{x}}\right)^{2}\left\{\begin{array}{l}
> \\
= \\
<
\end{array}\right\} \frac{1-\tau^{P}}{\tau^{P}} \cdot \frac{\sigma_{y}^{2} \tau^{P}+\rho_{x y} \sigma_{x} \sigma_{y}\left(1-\tau^{P}\right)}{\sigma_{x}^{2}\left(1-\tau^{P}\right)+\rho_{x y} \sigma_{x} \sigma_{y} \tau^{P}}
$$

2. $\rho<-\frac{\sigma_{x}}{\sigma_{y}} \cdot \frac{1-\tau^{P}}{\tau^{P}} \wedge \rho<-\frac{\sigma_{y}}{\sigma_{x}} \cdot \frac{\tau^{P}}{1-\tau^{P}}$ :

$$
\frac{\partial a^{*}}{\partial \tau^{P}}\left\{\begin{array}{l}
> \\
= \\
<
\end{array}\right\} 0 \Leftrightarrow\left(\frac{k_{y}}{k_{x}}\right)^{2}\left\{\begin{array}{l}
< \\
= \\
>
\end{array}\right\} \frac{1-\tau^{P}}{\tau^{P}} \cdot \frac{\sigma_{y}^{2} \tau^{P}+\rho_{x y} \sigma_{x} \sigma_{y}\left(1-\tau^{P}\right)}{\sigma_{x}^{2}\left(1-\tau^{P}\right)+\rho_{x y} \sigma_{x} \sigma_{y} \tau^{P}}
$$

3. $\rho>-\frac{\sigma_{x}}{\sigma_{y}} \cdot \frac{1-\tau^{P}}{\tau^{P}} \wedge \rho<-\frac{\sigma_{y}}{\sigma_{x}} \cdot \frac{\tau^{P}}{1-\tau^{P}}: \frac{\partial a^{*}}{\partial \tau^{P}} \geq 0 \forall k_{x}, k_{y}>0$

4. $\rho<-\frac{\sigma_{x}}{\sigma_{y}} \cdot \frac{1-\tau^{P}}{\tau^{P}} \wedge \rho>-\frac{\sigma_{y}}{\sigma_{x}} \cdot \frac{\tau^{P}}{1-\tau^{P}}: \frac{\partial a^{*}}{\partial \tau^{P}} \leq 0 \forall k_{x}, k_{y}>0$

Before we explain the economics behind this proposition, we first present a related result for the tax planning effort such that we can jointly discuss both aspects.

Proposition 3: Tax planning effort $b^{*}$ always increases in the corporate tax rate if tax planning is riskless. Otherwise, it can increase or decrease in the corporate tax rate. 
Proof: Differentiating (14) with respect to $\tau^{P}$ gives

$$
\frac{\partial b^{*}}{\partial \tau^{P}}=\underbrace{\frac{1-\tau^{A}}{1-\tau^{P}} \cdot \frac{k_{y}}{K+r \sigma^{2}}}_{>0}\left(\frac{K}{1-\tau^{P}}+\frac{2 r \tau^{P}}{K+r \sigma^{2}} B\right),
$$

with $B$ as defined in (17). As has already been shown in the proof of Proposition 2, we have $B>0$ if $\sigma_{y}^{2}=0$, making the term in in parentheses clearly positive. For positive risks of tax planning, all cases with $B>0$ as identified in Proposition 2 also imply increasing tax planning, whereas not all cases with $B<0$ lead to decreasing tax planning with respect to $\tau^{P}$ due to the positive term $K /\left(1-\tau^{P}\right)$.

For uncorrelated risks, we now get

$$
\left.\frac{\partial b^{*}}{\partial \tau^{P}}\right|_{\rho_{x y}=0}\left\{\begin{array}{c}
> \\
= \\
<
\end{array}\right\} 0 \Leftrightarrow \underbrace{\frac{K\left(K+r \sigma^{2}\right)}{2 r\left(\tau^{P}\right)^{2}\left(1-\tau^{P}\right)^{2}}}_{>0}\left\{\begin{array}{c}
> \\
= \\
<
\end{array}\right\} k_{x}^{2} \sigma_{y}^{2}-k_{y}^{2} \sigma_{x}^{2}
$$

To show that this partial derivative can be negative, we rewrite (21) as follows:

$$
\begin{aligned}
& \left.\frac{\partial b^{*}}{\partial \tau^{P}}\right|_{\rho_{x y}=0}<0 \\
\Leftrightarrow & K\left(K+r \sigma^{2}\right)<2 r\left(\tau^{P}\right)^{2}\left(1-\tau^{P}\right)^{2}\left(k_{x}^{2} \sigma_{y}^{2}-k_{y}^{2} \sigma_{x}^{2}\right) \\
\Leftrightarrow & \underbrace{\left(1-\tau^{P}\right)^{4} k_{x}^{4}+\left(\tau^{P}\right)^{4} k_{y}^{4}+2\left(\tau^{P}\right)^{2}\left(1-\tau^{P}\right)^{2} k_{x}^{2} k_{y}^{2}}_{>0} \\
& +r[\underbrace{\left(1-\tau^{P}\right)^{4} k_{x}^{2} \sigma_{x}^{2}+\left(\tau^{P}\right)^{4} k_{y}^{2} \sigma_{y}^{2}+3\left(\tau^{P}\right)^{2}\left(1-\tau^{P}\right)^{2} k_{y}^{2} \sigma_{x}^{2}}_{>0}-\underbrace{\left(\tau^{P}\right)^{2}\left(1-\tau^{P}\right)^{2} k_{x}^{2} \sigma_{y}^{2}}_{>0}]<0
\end{aligned}
$$


This inequality can only hold if the last (negative) term on the LHS dominates. This requires that operational productivity $k_{x}$ as well as tax risk $\sigma_{y}^{2}$ are large compared to tax planning productivity $k_{y}$ and operational risk $\sigma_{x}^{2}$. To prove the mere existence of such an effect, a numerical example is sufficient. Figure 1 shows the optimal level of tax planning as a function of the corporate tax rate for the parameter setting $\rho_{x y}=0, k_{x}=r=\sigma_{x}=\sigma_{y}=1, k_{y}=0.1, \tau^{A}=0.4$ :

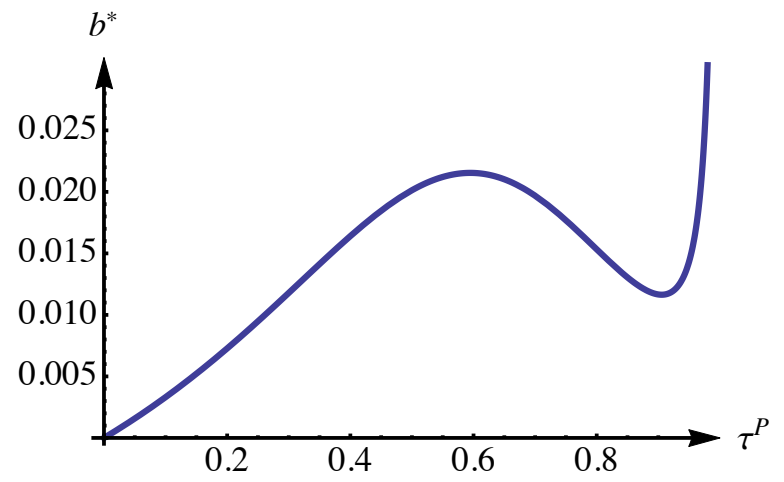

Figure 1: Optimal tax planning effort as a function of the corporate tax rate

For corporate tax rates in the interval $\tau^{P} \in[0.595,0.906]$ optimal tax planning decreases with increasing corporate tax rate.

Analogous arguments can be advanced for non-zero correlations. We do not include them in detail as this does not give any significant additional insights.

Intuitively, one would expect that tax planning effort increases with a larger corporate tax rate. Proposition 3 shows that this "normal" behavior always occurs if tax planning does not involve any separate risks $\left(\sigma_{y}^{2}=0\right)$. The reason can be seen by inspecting the 
fraction $K /\left(K+r \sigma^{2}\right)$ that displays the principal's risk-return trade-off. For $\sigma_{y}^{2}=0$ we arrive at

$$
\left.\frac{K}{K+r \sigma^{2}}\right|_{\sigma_{y}=0}=\frac{\left(1-\tau^{P}\right)^{2} k_{x}^{2}+\left(\tau^{P}\right)^{2} k_{y}^{2}}{\left(1-\tau^{P}\right)^{2} k_{x}^{2}+\left(\tau^{P}\right)^{2} k_{y}^{2}+r\left(1-\tau^{P}\right)^{2} \sigma_{x}^{2}}=\frac{k_{x}^{2}+\left(\frac{\tau^{P}}{1-\tau^{P}}\right)^{2} k_{y}^{2}}{k_{x}^{2}+\left(\frac{\tau^{P}}{1-\tau^{P}}\right)^{2} k_{y}^{2}+r \sigma_{x}^{2}} .
$$

This expression strictly increases in the corporate tax rate, which is due to the fact that with higher $\tau^{P}$, tax planning becomes more profitable without causing any additional risks. In order to make use of these effects, the principal increases the bonus coefficient $\alpha$, not only to keep the previous incentives of the nominal bonus coefficient intact, but additionally to account for the new trade-off. Since operational effort and tax planning are linked through the bonus coefficient, the increase in $\alpha$ implies that operational effort also increases with higher corporate taxes. In turn, this leads to an effect that we have termed "paradoxical" regarding the operational effort, explaining the related result in Proposition 2.

The other results of Propositions 2 and 3 can be explained in a similar way. Suppose $\sigma_{y}^{2}>0$ and uncorrelated risks. Now, an increase in the corporate tax rate still makes tax planning more profitable in expectation, but this comes at a cost since the risks of tax planning also increase. This affects the principal's risk-return trade-off, and it turns out that the net effect depends on the comparison between the "risk-adjusted" productivities $k_{y} / \sigma_{y}$ of tax planning and of operational effort $k_{x} / \sigma_{x}$. Since estimations 
of total tax risk are not publicly available, ${ }^{11}$ it is not possible to assess whether this is a likely case. However, (18) shows that unexpected tax effects on operational effort are basically possible. By contrast, previous models without tax planning effort show the irrelevance of corporate taxation on operational effort (Niemann, 2008, p. 285) or take the corporate tax rate as given (Desai/Dharmapala, 2006). Finally, with non-zero correlations, the logic of comparing risk-adjusted productivities still applies, but the formal expressions are much more cumbersone due to the additional correlation terms.

Proposition 3 and (14) also indicate why some firms are more tax aggressive than others. The parameters that determine the optimal level of tax planning are agentspecific (productivities and risk aversion), firm- or industry-specific (risk levels and correlation), and country-specific (tax rates). Against this background, it is not surprising that different firms show different degrees of tax avoidance. Given the multitude of different determinants of tax planning effort even in this simple model, it is likely that empirical studies of tax avoidance could benefit from these additional independent variables. In this regard, our theory is consistent with the results of a recent empirical paper by Francis et al. (2013) on the association between managerial ability and tax avoidance. They hypothesize and find a negative relation between managerial ability and tax avoidance (more able managers devote more effort to productive activities and concentrate less on tax avoidance). They measure tax avoidance by effective tax rates, i.e., the ratio of cash taxes paid over pre-tax income. A

\footnotetext{
${ }^{11}$ FIN 48 statements refer to uncertain income tax benefits, but not to legislative tax risks or risk from illegal tax planning. See, e.g., Mills et al. (2010).
} 
positive association between effective tax rates and managerial ability is then consistent with a negative relation between managerial ability and tax avoidance. In the context of our theory, managerial ability with respect to productive activities is represented by $k_{x}$, and we calculate the effective tax rate $(E T R)$ as the ratio of expected taxes over expected pre-tax income before reductions induced by tax planning. Thus, ETR is given by

$$
\operatorname{ETR}=\frac{\tau^{P}(\mathrm{E}[x]-\mathrm{E}[s]-\mathrm{E}[y])}{\mathrm{E}[x]-\mathrm{E}[s]}=\tau^{P}\left(1-\frac{\mathrm{E}[y]}{\mathrm{E}[x]-\mathrm{E}[s]}\right) .
$$

Inserting the expressions for the optimal solutions given in (9), (11), (13), (14) yields

$$
\begin{aligned}
E T R & =\tau^{P}\left[1-\frac{\frac{\left(1-\tau^{A}\right) \tau^{P}}{\left(1-\tau^{P}\right)} \frac{K}{K+r \sigma^{2}} k_{y}^{2}}{\left(1-\tau^{A}\right) \frac{K}{K+r \sigma^{2}} k_{x}^{2}-\frac{1}{2} \frac{1-\tau^{A}}{\left(1-\tau^{P}\right)^{2}}\left(\frac{K}{K+r \sigma^{2}}\right)^{2}\left(K+r \sigma^{2}\right)}\right] \\
& =\tau^{P}\left[1-\frac{2 \tau^{P}\left(1-\tau^{P}\right) k_{y}^{2}}{\left(1-\tau^{P}\right)^{2} k_{x}^{2}-\left(\tau^{P}\right)^{2} k_{y}^{2}}\right] .
\end{aligned}
$$

Differentiating ETR with respect to $k_{x}$ leads to

$$
\frac{\partial E T R}{\partial k_{x}}=\frac{4\left(\tau^{P}\right)^{2}\left(1-\tau^{P}\right)^{3} k_{x} k_{y}^{2}}{\left[\left(1-\tau^{P}\right)^{2} k_{x}^{2}-\left(\tau^{P}\right)^{2} k_{y}^{2}\right]^{2}}>0 .
$$

Hence, the implications of our model are consistent with the findings of Francis et al. (2013), but our argument is much broader than their hypothesis as we take into account 
the optimal adjustment of the incentive contract with respect to all parameters.

Moreover, comparing the cases of observable and unobservable efforts points to the impact of corporate governance on tax avoidance. We assume that better governance is associated with better observability of managerial efforts. Comparing (2) and (14) shows that better governed firms should ceteris paribus be more tax aggressive than others. Assuming further that owner-managed or family-owned firms are characterized by better observability of managerial efforts (or less managerial diversion of resources), our theoretical prediction would be that these firms are more tax aggressive than nonfamily firms. ${ }^{12}$

The next apparently paradoxical tax effect refers to the principal's objective function:

Proposition 4: For riskless tax planning, the principal's expected net cash flow $N$ strictly increases in $\tau^{P}$ for relatively high corporate tax rates $\tau^{P} \geq k_{x}^{2} /\left(k_{x}^{2}+k_{y}^{2}\right)$.

In general, the principal's expected net cash flow $N$ can increase or decrease in the corporate tax rate $\tau^{P}: \frac{\partial N}{\partial \tau^{P}}\left\{\begin{array}{l}> \\ = \\ <\end{array}\right\} 0$

Proof: Differentiating $N$ with respect to $\tau^{P}$ yields:

$$
\frac{\partial N}{\partial \tau^{P}}=\frac{1}{2} \cdot \frac{1-\tau^{A}}{1-\tau^{P}} \cdot \frac{1}{K+r \sigma^{2}} \cdot\left(\frac{K^{2}}{1-\tau^{P}}+\frac{z}{K+r \sigma^{2}}\right)
$$

12 The empirical results on tax aggressiveness of family firms by Chen et al. (2010) and Bauweraerts/Vandernoot (2013) are ambiguous. 
with $\quad z=2 K\left[\left(K+2 r \sigma^{2}\right)\left(\tau^{P} k_{y}^{2}-\left(1-\tau^{P}\right) k_{x}^{2}\right)-r K\left(\tau^{P} \sigma_{y}^{2}-\left(1-\tau^{P}\right) \sigma_{x}^{2}+\rho_{x y} \sigma_{x} \sigma_{y}\left(1-2 \tau^{P}\right)\right)\right]$

Consider first the case of riskless tax planning, i.e., $\sigma_{y}^{2}=0$. Then $z$ becomes

$\left.z\right|_{\sigma_{y}^{2}=0}=2 K\left[\left(K+2 r \sigma^{2}\right)\left(\tau^{P} k_{y}^{2}-\left(1-\tau^{P}\right) k_{x}^{2}\right)+r K\left(1-\tau^{P}\right) \sigma_{x}^{2}\right]$

Obviously, if $\tau^{P} k_{y}^{2} \geq\left(1-\tau^{P}\right) k_{x}^{2} \Leftrightarrow \tau^{P} \geq k_{x}^{2} /\left(k_{x}^{2}+k_{y}^{2}\right)$, then $\left.z\right|_{\sigma_{y}^{2}=0}>0$ and $N$ strictly increases in $\tau^{P}$.

A similar result emerges in the general case $\sigma_{y}^{2}>0$. Considering the limiting case of $\tau^{P} \rightarrow 1$, the partial derivative $\partial N / \partial \tau^{P}$ approaches infinity for any parameter setting, thus implying "paradoxical" effects for $N$ if corporate tax rates are very high. For less extreme cases, the correlation coefficient has to be taken into account.

For non-negative correlations $\rho_{x y} \geq 0$, "normal" tax effects prevail for small tax rates:

$\lim _{\tau^{P} \rightarrow 0} \frac{\partial N}{\partial \tau^{P}}=-\frac{\left(1-\tau^{A}\right) k_{x}^{4}\left(k_{x}^{2}+r\left(\sigma_{x}^{2}+2 \rho_{x y} \sigma_{x} \sigma_{y}\right)\right)}{2\left(k_{x}^{2}+r \sigma_{x}^{2}\right)^{2}} \leq 0$ for $\rho_{x y} \geq 0$

For negative correlations, however, paradoxical tax effects can occur even for very low tax rates close to zero: 


$$
\lim _{\tau^{P} \rightarrow 0} \frac{\partial N}{\partial \tau^{P}}>0 \Leftrightarrow \frac{k_{x}^{2}}{r}<-\sigma_{x}\left(\sigma_{x}+2 \rho_{x y} \sigma_{y}\right)
$$

Since $k_{x}^{2} / r>0$ this condition can hold only if $\sigma_{x} / \sigma_{y}<-2 \rho_{x y}$. Hence, a paradoxical tax effect for low tax rates requires a negative correlation coefficient and high tax risk. Paradoxical tax effects are more likely for high risk aversion and low operational productivity.

Figure 2 displays this paradoxical tax effect on expected net cash flow for the parameters $\rho_{x y}=-1, k_{x}=r=\sigma_{x}=\sigma_{y}=1, k_{y}=0.1, \tau^{A}=0.4$ and the corporate tax rate interval $\tau^{P} \in[0,0.404]$ :

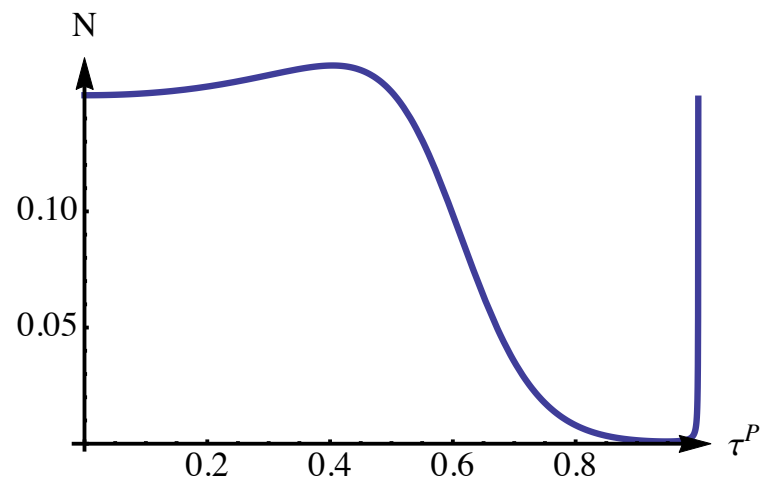

Figure 2: Principal's objective function as a function of the corporate tax rate (q.e.d.)

From the above discussion it follows that the likelihood of paradoxical tax effects essentially depends on the relation of the risk-adjusted productivities $\frac{k_{x}}{\sigma_{x}} / \frac{k_{y}}{\sigma_{y}}$. Paradoxical tax effects with respect to operational effort (increasing operational effort 
with increasing corporate tax rate) tend to occur if tax planning is a high-return-low-risk activity. By contrast, paradoxical tax effects on tax planning effort are more likely if tax planning is a low-return-high-risk activity compared to operational effort. Paradoxical tax effects on the principal's net cash flow (as shown in Figure 2) require some rather strong assumptions, i.e., a sufficiently negative correlation and tax planning as a lowreturn-high-risk activity.

To provide some more intuition for these unexpected effects we consider the behavior of the variance of the agent's remuneration:

Proposition 5: The effect of the corporate tax rate on the variance of the agent's compensation $\operatorname{Var}(s)$ is ambiguous: $\frac{\partial \operatorname{Var}(s)}{\partial \tau^{P}}\left\{\begin{array}{l}> \\ = \\ <\end{array}\right\} 0$.

Proof: The variance of the agent's compensation is given by $\operatorname{Var}(s)=\left(1-\tau^{A}\right)^{2} \alpha^{2} \sigma^{2}$. The algebraic sign of the partial derivative with respect to $\tau^{P}$ is ambiguous:

$$
\begin{aligned}
& \frac{\partial \operatorname{Var}(s)}{\partial \tau^{P}}=\frac{\left(1-\tau^{A}\right)^{2} 2 K}{\left(1-\tau^{P}\right)\left(K+r \sigma^{2}\right)^{2}}\left\{K\left(\sigma_{y}^{2} \frac{\tau^{P}}{1-\tau^{P}}+\rho_{x y} \sigma_{x} \sigma_{y}\right)\right. \\
& \left.\quad+\frac{2 r \sigma^{2}}{K+r \sigma^{2}}\left[\left(1-\tau^{P}\right) \tau^{P}\left(k_{y}^{2} \sigma_{x}^{2}-k_{x}^{2} \sigma_{y}^{2}\right)+\rho_{x y} \sigma_{x} \sigma_{y}\left(\left(\tau^{P}\right)^{2} k_{y}^{2}-\left(1-\tau^{P}\right)^{2} k_{x}^{2}\right)\right]\right\}
\end{aligned}
$$


Since $\left.\operatorname{Var}(s)\right|_{\tau^{P}=0}=\frac{\left(1-\tau^{A}\right)^{2} k_{x}^{4} \sigma_{x}^{2}}{\left(k_{x}^{2}+r \sigma_{x}^{2}\right)^{2}}>0$ and $\lim _{\tau^{P} \rightarrow 1} \operatorname{Var}(s)=+\infty, \frac{\partial \operatorname{Var}(s)}{\partial \tau^{P}}>0$ must hold for at least some values $\tau^{P}<1$.

The existence of a negative sign $\frac{\partial \operatorname{Var}(s)}{\partial \tau^{P}}<0$ depends on the parameter setting. For a zero corporate tax rate $\tau_{P}=0$ the partial derivative becomes $\left.\frac{\partial \operatorname{Var}(s)}{\partial \tau^{P}}\right|_{\tau_{P}=0}=\frac{2\left(1-\tau^{A}\right)^{2} k_{x}^{4}\left(k_{x}^{2}-r \sigma_{x}^{2}\right) \rho_{x y} \sigma_{x} \sigma_{y}}{\left(k_{x}^{2}+r \sigma_{x}^{2}\right)^{3}}$. Its algebraic sign therefore depends on the correlation coefficient and whether or not the risk-adjusted operational productivity exceeds the agent's coefficient of risk aversion:

$\left.\frac{\partial \operatorname{Var}(s)}{\partial \tau^{P}}\right|_{\tau_{p}=0}=0$ for $\rho_{x y}=0$
$\left.\frac{\partial \operatorname{Var}(s)}{\partial \tau^{P}}\right|_{\tau_{p}=0}>0 \Leftrightarrow\left(\frac{k_{x}^{2}}{\sigma_{x}^{2}}>r \wedge \rho_{x y}>0\right) \vee\left(\frac{k_{x}^{2}}{\sigma_{x}^{2}}<r \wedge \rho_{x y}<0\right)$
$\left.\frac{\partial \operatorname{Var}(s)}{\partial \tau^{P}}\right|_{\tau_{p}=0}<0 \Leftrightarrow\left(\frac{k_{x}^{2}}{\sigma_{x}^{2}}>r \wedge \rho_{x y}<0\right) \vee\left(\frac{k_{x}^{2}}{\sigma_{x}^{2}}<r \wedge \rho_{x y}>0\right)$

If $\frac{\partial \operatorname{Var}(s)}{\partial \tau^{P}}<0$ for $\tau^{P}=0$ it follows from continuity that $\frac{\partial \operatorname{Var}(s)}{\partial \tau^{P}}<0$ is also true for small values $\tau^{P}>0$.

If $\frac{\partial \operatorname{Var}(s)}{\partial \tau^{P}}<0$ holds for $\tau^{P}>0$ then an interior minimum $\tau_{0}^{P}$ of $\operatorname{Var}(s)$ exists. This is 
typically the case if tax planning is a low-return-high-risk activity. Numerical examples for different correlation coefficients can give an impression of the variance function. For the parameter setting $k_{x}=r=\sigma_{x}=\sigma_{y}=1, k_{y}=0.1, \tau^{A}=0.4$ used above, the following figures emerge for uncorrelated risks $\left(\rho_{x y}=0\right.$, LHS $)$ and the rather extreme case of a perfectly negative correlation $\left(\rho_{x y}=-1, \mathrm{RHS}\right)$ :
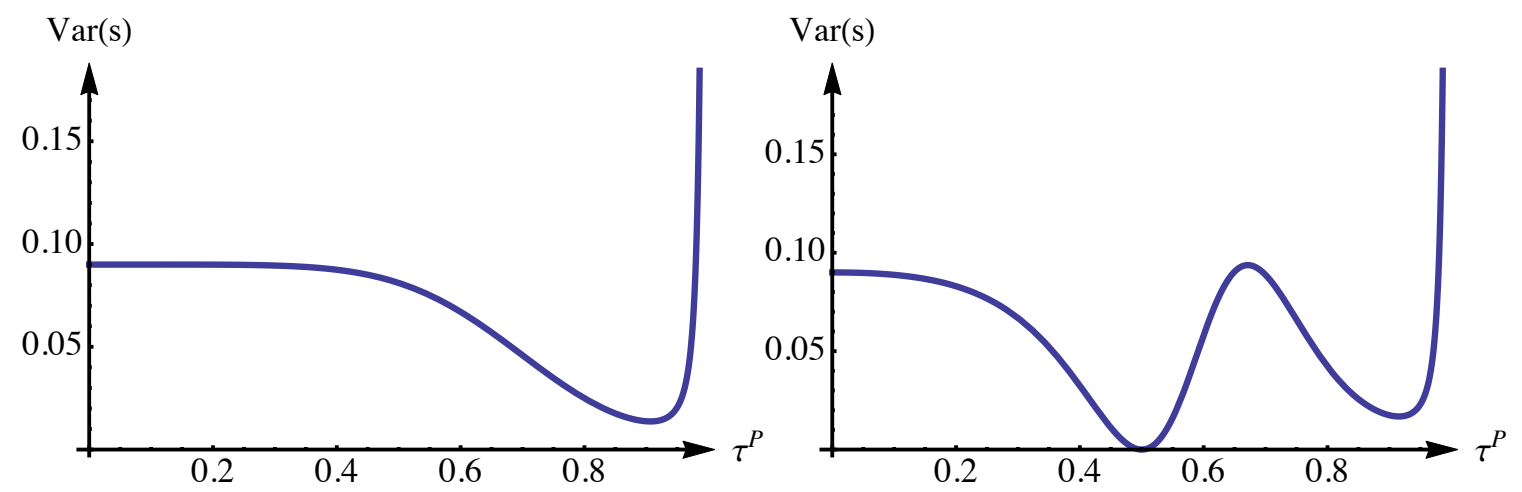

Figure 3: Variance of the agent's total remuneration as a function of the corporate tax rate

Starting with the LHS-figure, paradoxical tax effects can be explained as follows: With uncorrelated risks, the variance of after-tax cash flows has an interior minimum at $\tau_{0}^{P}$. Increasing the tax rate alleviates (aggravates) the trade-off between motivation and risk sharing if the tax rate is initially below (above) $\tau^{P}=\tau_{0}^{P}$, causing a basically positive impact on the bonus coefficient for relatively low tax rates. In addition, higher tax rates make tax planning more beneficial for the principal. Thus, at first it is profitable for the principal to increase the bonus coefficient, and the tax planning effort first increases in the tax rate. However, further increases of the tax rate impair the trade-off between 
motivation and risk. It turns out that this effect overcompensates the direct positive impact of a higher tax rate implying a net reduction of the tax planning effort. Regarding the operational effort, due to $k_{y} / \sigma_{y}<k_{x} / \sigma_{x}$ in our example and the results in Proposition 2, the effect of better risk sharing for higher tax rates in the range $\tau^{P}<\tau_{0}^{P}$ is eventually not sufficient to outweigh the decrease in the net benefit of operational efforts, thus leading to a negative relationship between operational effort and tax rates.

The variance of managerial compensation decreases with increasing tax rates because of the lower variance of after-tax cash flows, but increases due to the higher bonus coefficient. As a result, the variance of total remuneration can be roughly constant for small tax rates. For higher tax rates, the increasing variance of after-tax cash flows is overcompensated by the decreasing bonus coefficient, so that total remuneration variance decreases (until it finally approaches infinity for $\tau^{P} \rightarrow 1$ ).

In the extreme case of a perfectly negative correlation of operational risk and tax risk $\left(\rho_{x y}=-1\right)$, the variance of after-tax cash flows reaches zero at $\tau_{0}^{P}=\sigma_{x} /\left(\sigma_{x}+\sigma_{y}\right)$. At this tax rate, the principal is able to approach a solution equivalent to the observability case by renting the company to the agent and collecting the economic rent resulting from the cooperation. The principal's net cash flow is influenced by two different forces: on the one hand, the mitigated trade-off between motivation and risk sharing for tax rates $\tau^{P} \leq \tau_{0}^{P}$ improves the principal's utility. On the other hand, higher corporate tax rates reduce disposable net cash flows. As shown in Figure 1 following Proposition 4, the 
combination of these effects results in increasing net cash flows for higher tax rates in the interval $\tau^{P} \in[0,0.404]$. This effect can be explained by the impact of corporate taxation on the trade-off between motivation and risk sharing.

Our results clarify that tax systems in principal-agent settings exhibit risk-induced effects in excess of the traditional tax rate effects, tax base effects and time effects of taxation.

Variations of the wage tax rate $\tau^{A}$ yield results that are similar to a model with operational effort only. Adding tax planning opportunities does not alter these tax effects. The optimal bonus coefficient does not depend on the wage tax rate $\left(\partial \alpha^{\tau} / \partial \tau^{A}=0\right)$, the optimal effort levels decrease linearly with increasing wage tax rate $\left(\frac{\partial a^{*}}{\partial \tau^{A}}=-\frac{K k_{x}}{K+r \sigma^{2}}<0, \frac{\partial b^{*}}{\partial \tau^{A}}=-\frac{\tau^{P}}{\left(1-\tau^{P}\right)} \frac{K k_{y}}{K+r \sigma^{2}}<0\right)$, the optimal fixed salary increases $\left(\partial S_{0}^{\tau} / \partial \tau^{A}>0\right)$, the principal's objective function decreases monotonically with increasing wage tax rate $\left(\partial N^{\tau} / \partial \tau^{A}<0\right)$.

\section{Summary and conclusions}

Tax effects are typically neglected in principal-agent models. Formal agency relationships are rarely considered in the tax avoidance literature. We try to bring together these branches of the literature by modelling tax planning effort as a distinct managerial decision variable. 
We integrate wage taxation at the agent's level and corporate taxation at the principal's level into a principal-agent model of the LEN type. We analyze the effects of these two levels of taxation on optimal incentive contracts. Our (multi-task) model takes two different types of effort into account, i.e., the agent can provide operational effort as well as tax planning effort. Tax planning effort covers legal or illegal tax planning and can include profit taxation, transaction taxes, tariffs, or the tax-optimal design of legal structures and transactions.

By explicitly modeling tax planning as a managerial action variable we are able to show a variety of apparently paradoxical tax effects. First, the principal's net cash flow can increase or decrease with increasing corporate tax rates. Second, operational effort can increase or decrease with increasing corporate tax rates. Third, even tax planning effort can increase or decrease with increasing corporate tax rates. These results can be explained by the interdependence of motivation, risk sharing, and the impact of corporate taxation on the variance of managerial remuneration.

In contrast to corporate taxation, wage taxation of the managerial compensation always exhibits the expected effects: both effort levels as well as the principal's objective function decrease with increasing wage tax rate.

The results of this paper are novel and have not yet been shown in the literature. Neither the principal-agent literature nor the public finance literature offers comparable insights into the optimal level of tax planning activities and the spill-over effects on optimal operational effort. Our results can be utilized by both taxpayers and the fiscal 
authorities. Taxpayers get additional information about the optimal design of compensation contracts in the presence of taxes. The tax legislator being aware of the emerging tax effects can improve estimations of the impact of tax rate variations and the mix of corporate taxation and wage taxation.

Furthermore, our model provides theoretical explanations why some firms are more tax aggressive than others. In our terminology, being more tax aggressive is equivalent to having a higher optimal tax planning effort, meaning that all parameters that affect tax planning effort are determinants of tax avoidance. Ideally, all these determinants should be integrated, i.e., operational productivity, tax planning productivity, operational risk, tax risk, correlation of operational and tax risk, personal income tax rate, corporate income tax rate, and corporate governance characteristics. As a consequence, these determinants should be integrated as independent variables into empirical models of tax avoidance. Although measuring these determinants of tax avoidance or finding suitable proxies for them is difficult, omitting one or more of these variables potentially reduces the explanatory power of empirical studies.

Whereas the empirical tax avoidance literature uses scoring models of governance quality, our model is dichotomous and refers to (non-)observability of efforts. However, our model permits the unambiguous prediction that (better governed) firms with observable effort should be more tax aggressive.

Apart from the LEN assumptions that have been extensively discussed in the literature, our model is subject to several limitations. First, the effort levels may be chosen 
independently. This assumption implies that tax planning can be profitable even without operational activity. However, we think that this situation may arise in reality, because our tax planning definition is very broad and covers various taxes, charges, and tariffs and can also refer to purely financial activities. This setting corresponds to jurisdictions with tax loss carrybacks in which tax reimbursements without operating profit are possible in single periods. Moreover, despite the assumption of independent efforts, the model predicts a strictly positive relationship of operational and tax planning effort, This result excludes "pure" tax planning without operational activity.

Second, we assume symmetric taxation, i.e., losses entitle to immediate tax reimbursements that are uncommon in real-world tax systems. This assumption is due to the LEN framework that requires linearity. This assumption is further justified when the principal receives positive exogenous income that can be used for loss-offset and that is not managed by the agent.

Our model can be extended in several directions. To avoid pathological cases with infinite values, upper limits on effort levels and tax rates could be considered. To approach the independence of effort levels, a range of feasible effort ratios could be introduced. As a step towards more complicated tax systems, asymmetric taxation, i.e., loss-offset restrictions could be integrated into the model. However, the arising mathematical difficulties resulting from violations of the LEN assumption should be kept in mind.

A model with two bonus coefficients would be a further extension. A separate bonus 
coefficient for operational effort and for tax planning permits a more accurate incentivization of the activities desired by the principal. However, it can be shown that the emerging effects are quite similar to those in our model.

Another research direction points to the analysis of incentive-related time effects of taxation that require the implementation of multi-period agency models. Currently, these models including taxation are not available.

\section{References}

Allingham, M./Sandmo, Agnar (1972): Income tax evasion: a theoretical analysis, in: Journal of Public Economics 1, 323-338.

Armstrong, Christopher S./Blouin, Jennifer L./Larcker, David F. (2012): The Incentives for Tax Planning, in: Journal of Accounting and Economics 53, 391-411.

Banerjee, Anindya/Besley, Timothy (1990): Moral Hazard, Limited Liability and Taxation: A Principal-Agent Model, in: Oxford Economic Papers 42, 46-60.

Bauweraerts, Jonathan/Vandernoot, Julien (2013): Allowance for Corporate Equity and Tax Aggressiveness: Do Family Firms Differ from Non-Family Firms?, in: Journal of Management Research 5, 1-16.

Chen, Shuping/Chen, Xia/Cheng, Qiang/Shevlin, Terry (2010): Are family firms more tax aggressive than non-family firms?, in: Journal of Financial Economics 95, 41-61.

Chen, Kong-Pin/Chu, C. Y. Cyrus (2005): Internal control vs. external manipulation: A model of corporate income tax evasion, in: RAND Journal of Economics 36, 151-164.

Cloyd, C. Bryan/Pratt, Jamie/Stock, Toby (1996): The Use af Financial Accounting Choice 
to Support Aggressive Tax Positions: Public and Private Firms, in: Journal of Accounting Research 34, 23-43.

Crocker, Keith J./Slemrod, Joel (2005): Corporate tax evasion with agency costs, in: Journal of Public Economics 89, 1593-1610.

Datar, Srikant/Kulp, Susan C./Lambert, Richard A. (2001): Balancing Performance Measures, in: Journal of Accounting Research 39, 75-92.

Desai, Mihir A./Dharmapala, Dhammika (2006): Corporate tax avoidance and highpowered incentives, in: Journal of Financial Economics 79, 145-179.

De Waegenaere, Anja/Sansing, Richard C./Wielhouwer, J. (2010): Financial Accounting Measures of Tax Reporting Aggressiveness, Tuck School of Business Working Paper No. 2010-83, http://ssrn.com/abstract=1697536.

Dyreng, Scott D./Hanlon, Michelle/Maydew, Edward L. (2010): The Effects of Executives on Corporate Tax Avoidance, in: The Accounting Review 85, 1163-1189.

Ewert, Ralf/Wagenhofer, Alfred (2012): Earnings Management, Conservatism, and Earnings Quality, in: Foundations and Trends in Accounting 6, 65-186.

Fellingham, John C./Wolfson, Mark A. (1985): Taxes and Risk Sharing, in: The Accounting Review 40, 10-17.

Feltham, Gerald A./Xie, Jim (1994): Performance Measure Congruity and Diversity in Multi-Task Principal/Agent Relations, in: The Accounting Review 69, 429-453.

Francis, Bill B./Sun, Xian/Wu, Quiang (2013): Managerial Ability and Tax Avoidance, SSRN Working Paper, http://ssrn.com/abstract=2348695.

Frank, Mary Margaret/Lynch, Luann J./Rego, Sonja O. (2009): Tax Reporting Aggressiveness and Its Relation to Aggressive Financial Reporting, in: The Accounting Review 84, 467-496.

Göx, Robert F. (2008): Tax Incentives for Ineffcient Executive Pay and Reward for Luck, Review of Accounting Studies 13, 452-478. 
Halperin, Robert M./Kwon, Young K./Rhodes-Catanach, Shelley C. (2001): The Impact of Deductibility Limits on Compensation Contracts: A Theoretical Examination, in: Journal of the American Taxation Association 23, Supplement, 52-65.

Hanlon, Michelle/Slemrod, Joel (2009): What does tax aggressiveness signal? Evidence from stock price reactions to news about tax shelter involvement, in: Journal of Public Economics 93, 126-141.

Hemmer, Thomas (2004): Lessons Lost in Linearity: A Critical Assessment of the General Usefulness of LEN Models in Compensation Research, in: Journal of Management Accounting Research 16, 149-162.

Holmström, Bengt/Milgrom, Paul (1987): Aggregation and Linearity in the Provision of Intertemporal Incentives, in: Econometrica 55, 303-328.

Holmström, Bengt/Milgrom, Paul (1991): Multitask Principal-Agent Analyses: Incentive Contracts, Asset Ownership, and Job Design, in: Journal of Law, Economics, \& Organization 7, 24-52.

Mills, Lillian F. / Robinson, Leslie A. / Sansing, Richard C. (2010): FIN 48 and Tax Compliance, in: The Accounting Review 85, 1721-1742.

Niemann, Rainer (2004): Tax Rate Uncertainty, Investment Decisions, and Tax Neutrality, in: International Tax and Public Finance 11, 265-281.

Niemann, Rainer (2008): The Effects of Differential Taxation on Managerial Effort and Risk Taking, in: FinanzArchiv Public Finance Analysis 64, 273-310.

Niemann, Rainer (2011): The Impact of Tax Uncertainty on Irreversible Investment, in: Review of Managerial Science 5, 1-17.

Organization for Economic Cooperation and Development (2013a) OECD Tax Database, Top marginal combined personal incomes tax rates on gross wage for a single individual. http://www.oecd.org/tax/tax-policy/Table\%20I.7_Mar_2013.xlsx. Accessed 20 May 2013 
Organization for Economic Cooperation and Development (2013b) OECD Tax Database Basic (non-targeted) corporate income tax rates. http://www.oecd.org/tax/taxpolicy/Table\%20II.1_May\%202013.xlsx. Accessed 20 May 2013

Phillips, John D. (2003): Corporate Tax-Planning Effectiveness: The Role of Compensation-Based Incentives, in: The Accounting Review 78, 847-874.

Radulescu, Doina (2012): The Effects of a Bonus Tax on Manager Compensation and Welfare, in: Finanzarchiv - Public Finance Analysis 68, 1-16.

Rego, Sonja Olhoft/Wilson, Ryan (2012): Equity Risk Incentives and Corporate Tax Aggressiveness, in: Journal of Accounting Research 50, 775-809.

Spremann, Klaus (1987): Agent and Principal, in: Bamberg, Günter/Spremann, Klaus (Hrsg.): Agency Theory, Information, and Incentives, Springer-Verlag, Berlin, Heidelberg, 3-37.

Voßmerbäumer, Jan (2013): Incentive Effects and the Income Tax Treatment of Employer-Provided Workplace Benefits, in: Review of Managerial Science 7, 61-84.

Wagenhofer, Alfred (2003): Accrual-Based Compensation, Depreciation, and Investment Decisions, in: European Accounting Review 12, 287-309.

Wolfson, Mark A. (1985): Tax, Incentive, and Risk-sharing Issues in the Allocation of Property Rights: The Generalized Lease-or-Buy Problem, in: Journal of Business 58, 159171. 